\title{
A Cost-Benefit Analysis of Implementing Urban Heat Island Adaptation Measures in Small and Medium-Sized Cities in Austria
}

\begin{abstract}
Urban heat islands are an increasing concern even in small- to medium-sized cities, although these areas are still understudied especially in terms of the economic feasibility of adaptation options. This paper uses adaptation scenarios produced by an urban climate model as inputs to a social costbenefit analysis in three small- to medium-sized cities in Austria: Mödling, Klagenfurt and Salzburg. The adaptation scenarios, which consider measures such as increasing the reflectivity of different sealed surfaces (referred to as the White City scenario) as well as greening measures (i.e., the Green City scenario), show decreases in the number of hot days $\left(\mathrm{T}_{\max } \geq 30^{\circ} \mathrm{C}\right)$ when implemented. Benefits include reductions in heat-related mortality, which are modeled based on trends of daily mortality and climate data, reduced morbidity, productivity loss and numerous urban ecosystem services. The results demonstrate favorable benefit-cost ratios of a combination of measures (White and Green City) of 1.27, 1.36 and 2.68 for Mödling, Klagenfurt and Salzburg, respectively, indicating positive economic grounds for supporting policies in line with the adaptation scenarios. Furthermore, results of the Green City vs White City showed higher benefits for the combined and Green City scenarios despite higher costs for each of the cities.
\end{abstract}

Keywords: Economic valuation, urban heat island, heat-related mortality, cost-benefit analysis 


\section{Introduction}

Cities are affected by a phenomenon known as the urban heat island effect (UHI) in which temperatures are higher than the surrounding rural areas (Oke, 1973). This is the result of higher amounts of impervious surfaces, a lack of vegetation in urban areas as well as the presence of concentrated urban structures (Oke, 1982). Thus, heat waves in cities are more extreme than in rural areas, and in the past, they have contributed to loss of life. During the heat wave in 2003, for example, more than 30,000 people in Europe are estimated to have died due to heat (UNEP, 2004). Future climate scenarios indicate higher frequency and duration of heat waves over the next century, which will further increase health risks (Revi et al., 2014) and mortality (Gasparrini et al., 2017). For example, by 2071 to 2100 in Europe, it is predicted that more than 150,000 people will die annually due to increased heat (Forzieri et al., 2017). Other negative effects of the UHI include increasing air pollution and the general reduction in the thermal comfort of urban dwellers (Harlan and Ruddell, 2011).

Although the UHI effect has been studied in different ways, urban climate modelling allows adaptation scenarios to be simulated with respect to their effect in decreasing the number of tropical nights $\left(\mathrm{T}_{\min } \geq 20^{\circ} \mathrm{C}\right.$ ), summer days $\left(\mathrm{T}_{\max } \geq 25^{\circ} \mathrm{C}\right.$ ), and hot days $\left(\mathrm{T}_{\max } \geq 30{ }^{\circ} \mathrm{C}\right.$ ), which are indicators for the urban heat loads. Several large cities have already been simulated using urban climate models, e.g., Toulouse, France (Hidalgo et al., 2008) and Singapore (Mughal et al., 2019) but there is a lack of studies that have applied urban climate models to small and medium-sized cities, which are also at risk of impacts from the UHI. This remains a largely understudied research area, not only with respect to UHI research (Oswald et al., 2020) but also in terms of green infrastructure planning and ecosystem services (Shackleton et al., 2018).

As both urbanization and the effects of the UHI will continue to increase over the next century, urban planners need guidance on which adaptation measures to implement. A cost-benefit analysis (CBA) can provide one instrument for comparing the economic viability of a range of adaptation scenarios. Different adaptation measures can be valued based on information in the literature or from companies selling different adaptation solutions. The benefits, in contrast, are more difficult to quantify as they include reductions in mortality and morbidity, savings as a result of increased productivity associated with lower numbers of hot days, and numerous urban ecosystem services (Bolund and Hunhammer, 1999). Although green roofs can reduce the UHI effect through increased cooling (Zhang et al., 2019), they can also decrease energy consumption through provision of insulation, prevent runoff from entering the sewer system, and increase house prices since they are aesthetically pleasing (Bianchini and Hewage, 2012). There have been examples of monetary evaluation of these types of benefits appearing in the literature (see e.g., Dehnhardt, 2014), but CBAs of UHI adaptation scenarios are still rare. An exception is the recent study by Johnson and Geisendorf (2019), who evaluated the financial viability of sustainable urban drainage systems (SUDS) for a neighborhood in Berlin.

To fill the gap in this area, the aim of this paper is to undertake a cost benefit analysis of adaptation scenarios produced using an urban climate model applied to smaller cities in Austria, i.e., Mödling, Klagenfurt and Salzburg, with populations of around 20,000, 100,000 and 150,000, respectively. The methodology applied here draws upon the work of Johnson and Geisendorf (2019) but scales this upward from a neighborhood to a city level. Costs are calculated for each scenario and 
compared with monetary valuations of a range of benefits including reductions in heat-related mortality, morbidity, and productivity loss, along with an extensive set of urban ecosystem service benefits to calculate the net present value, the benefit-cost ratio, and the benefit and cost efficiencies.

\section{Methods}

Figure 1 provides a conceptual framework for the implementation of the social CBA. Each of these five components is described in more detail below.

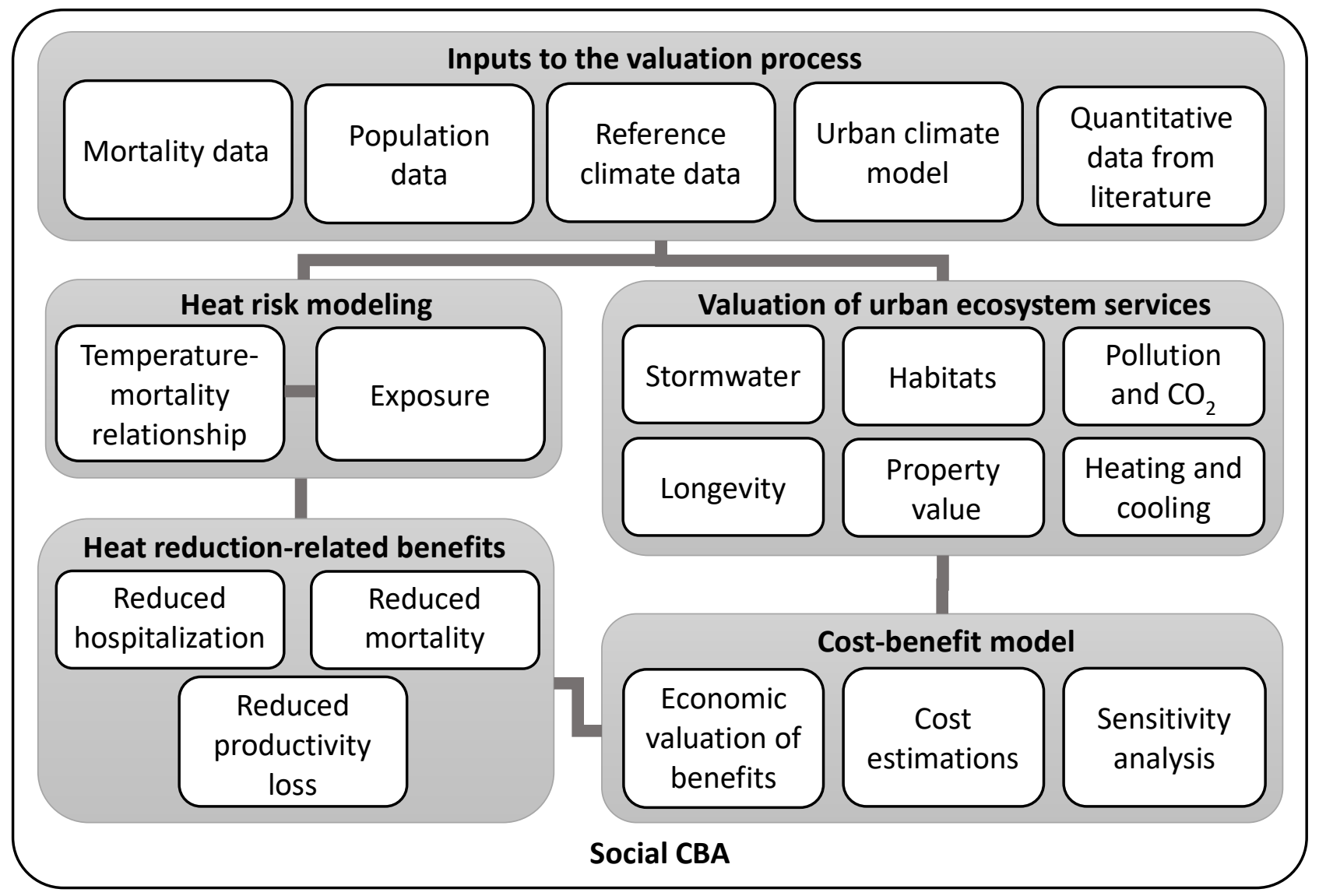

Figure 1. Conceptual framework for the steps in the social CBA.

\subsection{Inputs to the valuation process}

Daily all-cause mortality counts for 2003-2017 and population data from 2017 on a $250 \mathrm{~m} \mathrm{x}$ $250 \mathrm{~m}$ raster for all three cities were provided by Statistik Austria. Reference climate data, i.e., maximum daily temperature, mean daily temperature, precipitation, sunshine duration and air pressure at the local weather stations of Mödling (Gumpoldkirchen, 4802', 16²16', 219 m.a.m.s.l.), Klagenfurt (Klagenfurt-Airport, 46³9', 14²0’, 447 m.a.m.s.l.) and Salzburg (Salzburg-Airport, $47^{\circ} 47^{\prime}, 13^{\circ} 1^{\prime}$, 430 m.a.m.s.l.), were provided by the Zentralanstalt für Meterologie und Geodynamik (ZAMG). The urban climate model MUKLIMO_3, developed by the German Meteorological Service (Sievers, 1995), and the cuboid method approach (Früh et al., 2011) provided inputs to the CBA in 
the form of decreases in the number of hot days $\left(\mathrm{T}_{\max } \geq 30{ }^{\circ} \mathrm{C}\right)^{1}$ when different adaptation measures are implemented. There are three main types of scenarios: (i) the Green City, which includes the addition of green roofs, trees, low vegetation, and the unsealing of impervious surfaces ${ }^{2}$; (ii) the White City, which considers measures such as increasing the reflectivity (or albedo) of all roofs, building facades, and streets in land use classes with main urban building areas (i.e., land use classes 1-7 of the Urban Atlas; and (ii) the combined scenario of Green and White City measures. These scenarios are implemented in the urban climate model either by changing the model parameters in those locations that contain buildings and streets or by changing the proportions of land use to include greener surfaces. More details can be found in (Oswald et al., 2020) ${ }^{3}$. The size of the areas affected by the implementation of individual adaptation measures for each city are shown in Table 1.

Table 1. Size of areas affected $\left(\mathrm{m}^{2}\right)$ by implementation of the adaptation scenarios in each city.

\begin{tabular}{llccr}
\hline & & Mödling & Klagenfurt & Salzburg \\
\hline \multirow{2}{*}{ White City } & High albedo roofs & $2,283,835$ & $7,219,888$ & $10,292,202$ \\
& High albedo walls & $2,552,780$ & $11,431,396$ & $12,187,675$ \\
& High albedo pavement & $1,474,701$ & $12,000,959$ & $14,179,096$ \\
\hline \multirow{2}{*}{ Green City } & Green roofs & 557,591 & $2,087,032$ & $2,733,091$ \\
& Unsealing & 413,131 & $3,553,229$ & $3,993,866$ \\
& Trees & 920,926 & 688,174 & $1,018,387$ \\
& Low vegetation & 103,574 & $2,629,576$ & $1,815,184$ \\
\hline
\end{tabular}

Quantitative data from the literature were also used to inform reduced morbidity, decreased productivity loss and the valuation of urban ecosystem services obtained through green measures, as described in the following.

\subsection{Heat risk modeling}

We employed a distributed lag nonlinear model (Gasparrinia et al., 2010) to estimate the temperature-mortality relationship while accounting for lagged effects and nonlinearity. By

${ }^{1}$ The inputs were available as $20 \mathrm{~m}$ x $20 \mathrm{~m}$ rasters for Mödling and $100 \mathrm{~m}$ x $100 \mathrm{~m}$ rasters for Klagenfurt and Salzburg, and all maps were aggregated to $250 \mathrm{~m}$ x $250 \mathrm{~m}$ to align with the mortality and population data.

${ }^{2}$ We assumed an increase to $50 \%$ of roofs (excluding land use classes with old roofs) to be greened, a $50 \%$ increase in the number of trees, and a reduction of sealed surfaces by $30 \%$ to low vegetation (excluding industry and military land use classes).

${ }^{3}$ For the current analysis, aggregation to a $250 \mathrm{~m} \times 250 \mathrm{~m}$ resolution from the original resolutions implemented in the urban climate model as exemplified in (Oswald et al., 2020) was performed to align with the resolution of the mortality and population data. 
incorporating lagged effects and the nonlinearity of the exposure-response function, we can capture the increases in risk of mortality due to temperature. Although the model does not consider heat waves, the main effects of temperature are captured within the model, and additional effects of heat waves only bring about marginal changes in the risk (Gasparrini and Armstrong, 2011). The quasiPoisson regression model (1) defines a cross-basis function $\left[C B\left(\right.\right.$ Temp $\left.\left._{t}\right)\right]$ for lagged responses to temperature with a quadratic B-spline. We chose two internal knots of temperature with 4 degrees of freedom for the natural cubic spline to account for lagged days, with a maximum lag of 14 days as follows:

$$
\begin{aligned}
& Y_{t} \sim \text { Poisson }\left(\mu_{t}\right) \\
& \mu_{t}=\alpha+C B\left(\text { Temp }_{t}\right)+N S\left(\text { Time }_{t}, 8 d f / \text { year }\right)+\text { DoW }_{t}+\text { SunDur }_{t} \\
& \quad+\text { Airpress }_{t}+\text { Site }_{t}
\end{aligned}
$$

(1Error!

Bookmark

not

defined.)

where we controlled for sunshine duration $\left(\right.$ SunDur $\left._{t}\right)$ on day $t$, air pressure $\left(\right.$ Airpress $\left._{t}\right)$, days of the week $\left(D O W_{t}\right)$, and seasonality and long-term trends by including a natural spline of time $\left[N S\right.$ Time $_{t}, 8 d f /$ year $\left.)\right]$. We included Site $t$ as a dummy variable to include all cities into one model with dummy coding. The results of the model associating all-cause mortality and temperature as the risk accumulated over the lag period is displayed in Figure 1. We obtained empirical estimates of confidence of the exposure-response function through Monte Carlo simulations, taking random samples of the original parameters of the cross-basis. In Figure 1, the grey shaded region corresponds to $95 \%$ confidence intervals.

\section{Overall cumulative association}

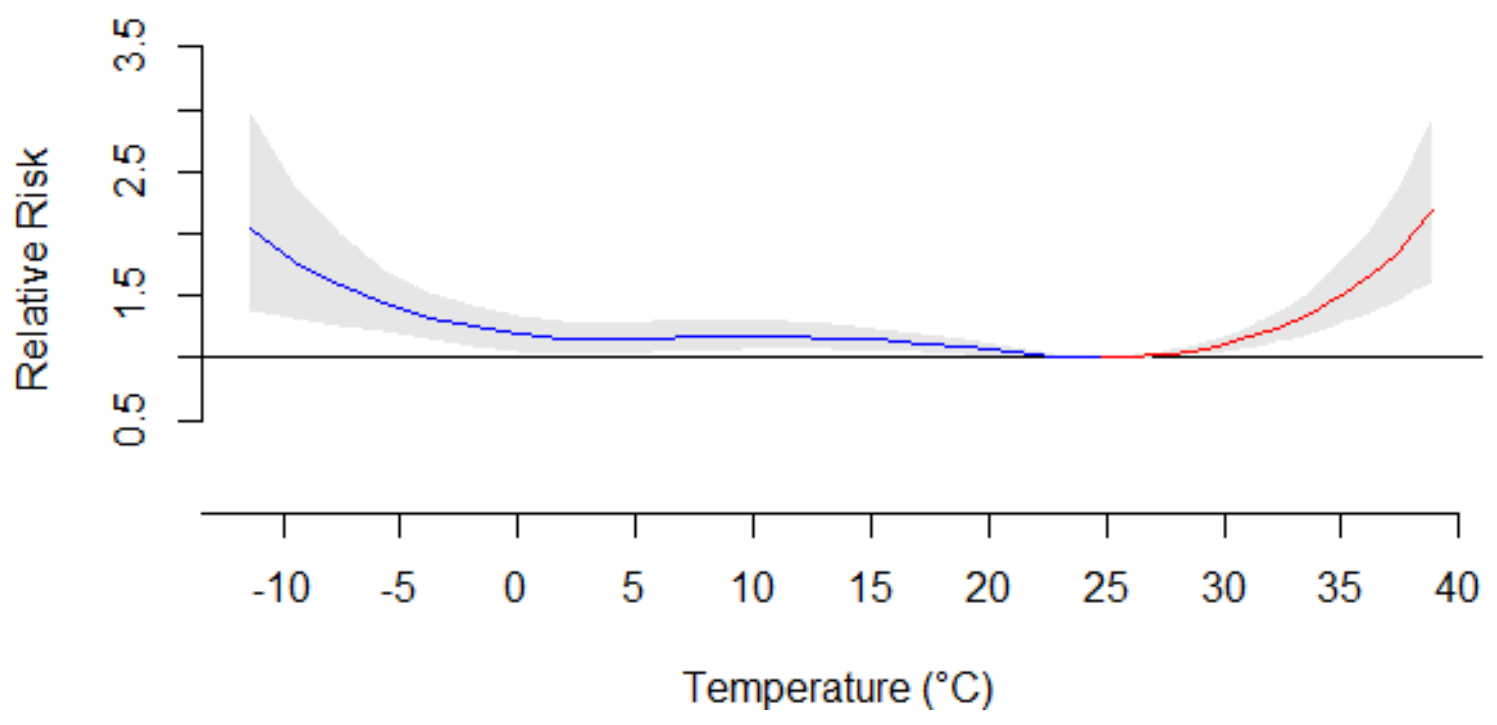

Figure 2. Overall cumulative exposure-response function with confidence intervals as the grey shaded region.

\subsection{Heat reduction-related benefits}


The number of attributable deaths due to hot days is calculated according to Gasparrini and Leone (2014) using the forward perspective. The minimum mortality temperature corresponding to the minimum mortality over the study period was used to calculate the cumulative relative risk centered at $30^{\circ} \mathrm{C}$. In a spatially explicit approach, we quantified the reduced heat-related mortality counts $\left(D_{\text {red,c }}\right)$ over the areas of the cities individually as follows:

$$
\sum_{c=1}^{n} D_{r e d, c}=\frac{A F \times T D}{Y \times P o p_{t o t}} \times \frac{H D_{r e d, c} \times P o p_{c}}{H D_{a v g, c}}
$$

(2Error!

Bookmark

not

defined.)

where $A F$ is the attributable fraction of deaths due to heat, $T D$ is the total deaths over the time period in a city, and $Y$ is the total number of years in the time period. To obtain a heat-related mortality rate, we divided by the total average population of each city over the years $\left(\mathrm{Pop}_{t o t}\right)$. To estimate the total average annual reduced heat-related mortality, we employed the population raster and the scenarios from the urban climate model, which provided the current average annual number of hot days $\left(H D_{a v g, c}\right)$ and the reduced number of hot days $\left(H D_{\text {red,c }}\right)$ in each cell $(c)$ given the adaptation measures implemented. Given the population in 2017 of each cell $\left(P_{o} p_{c}\right)$, we used this spatiallyexplicit approach to address exposure to heat risk and summed over the total number of cells $(n)$ to find the total average annual reduced heat-related mortality ${ }^{4}$, propagating this reduction for a 50 -year time horizon. As an example, Figure S1 in the Supplementary Material displays the raster plots of the spatial variables used in equation (2) for the district of Mödling. To estimate the societal value of reducing mortality risk, we adopted the value of a statistical life (VSL) approach (European Commission, 2014), which is the value that society places on avoiding an increased mortality risk. We valued the reduction of mortality risk using the estimate of VSL for Austria from Viscusi and Masterman (2017) at 8,157,000 $€$ and refrained from discounting future years on the grounds that society does not value future lives saved any differently than lives saved today in short and medium terms (Frederick, 2003; Robinson et al., 2019).

With this methodology, we did not employ different exposure-response functions for different age groups as has been done in other studies (e.g., Karlsson and Ziebarth, 2018). This is because we did not find statistically significant differences between the relative risks of the population with >65 years of age and the general population and, therefore, applied the same exposure-response function for the whole population in each city.

Due to a lack of hospitalization data at the city level, we adopted a linear approach to estimating reduced morbidity with the aforementioned combination of adaptation measures. We assumed 102 patient days are expected for every heat-related death (Donaldson et al., 2001; Hunt et al., 2017). We obtained the average daily cost of hospital stays for each of the states in which the cities are located

${ }^{4}$ Since the domains of the rasters from the urban climate model included areas outside each of the city limits, the exposed population included in the reduced heat-related mortality valuation included population sizes of approximately 60,000, 220,000 and 330,000 for Mödling, Klagenfurt and Salzburg, respectively. 
and averaged these over the years from 2008-2017, for which data were available. Given that patients are forced to spend their time outside of typical activities, we valued a reduced loss of time, valuing the quality of life year $(100,000 €)$ at 75\% (Karlsson and Ziebarth, 2018).

To value productivity losses associated with the reduced number of hot days, we assumed an average reduced worker productivity of $7 \%$ on a hot day (Vöhringer et al., 2017) given that productivity losses of $3 \%$ can be measured at temperatures of $26^{\circ} \mathrm{C}$ and productivity losses of $12 \%$ at $36^{\circ} \mathrm{C}$ (Bux, 2006). Although this approach does not consider the duration or intensity of exceedance of the temperature threshold, we believe this average estimate may underestimate the degree of productivity loss as the lower temperature range is not considered in our study (i.e., $26-30^{\circ} \mathrm{C}$ ). This estimate furthermore assumes an even distribution of economic activity for each day and that all workers are affected equivalently regardless of sector or availability of air conditioning.

We estimated the equivalent annual loss in gross regional product $\left(G R P_{\text {loss }}\right)$ similar to Hübler et al. (2007) but scaling down to the city level using a per capita weighted approach as follows:

$$
G R P_{\text {loss }}=H D \times \frac{G R P+\left(\frac{p}{1-p} \times G R P\right)}{365} \times w \times p \times P o p
$$

(3Error!

where $H D$ is the average number of hot days reduced per year, $G R P$ is the current per capita gross regional product (i.e., of 2016), $p$ is the average productivity loss on hot days (7\%), $w$ is the wage in 2016 (i.e., 69\%) and Pop is the population of the city in 2016.

\subsection{Valuation of urban ecosystem services}

Green measures including green roofs, trees, low vegetation and unsealing provide numerous additional benefits beyond those of white measures. The benefits were quantified as urban ecosystem services (Bolund and Hunhammer, 1999) using the methodology outlined in Johnson and Geisendorf (2019).

With the unsealing of surfaces, less stormwater runoff is generated that would otherwise be conveyed to treatment plants. Using the meteorological data from 2003-2017, we took the average precipitation over the years to be 660, 989 and $1151 \mathrm{~mm} / \mathrm{yr}$ for Mödling, Klagenfurt and Salzburg, respectively. As a regulating ecosystem service, we valued the runoff reduction according to the current sewer system use charge on sealed surface areas at $2.40 € / \mathrm{m}^{2}$ in Mödling and $2.20 € / \mathrm{m}^{2}$ in Klagenfurt and Salzburg, assuming a 50\% reduction for green roofs and a $100 \%$ reduction for unsealing surfaces by converting to low vegetation (Prokop et al., 2011).

Heating and cooling savings are two benefits arising from green roof implementations in the form of regulating ecosystem services. Green roofs provide additional insulation compared to conventional roofs (Berardi et al., 2015). By comparing the difference in thermal conductivity between green $\left(R_{G R}\right)$ and conventional $\left(R_{\text {conv }}\right)$ roofs (Clark et al., 2008) as well as the heating $\left(H D D_{15^{\circ} \mathrm{C}}\right)$ and cooling degree days $\left(C D D_{18.3^{\circ} \mathrm{C}}\right)$ (i.e., measures of the heating and cooling loads given threshold temperatures and reference climate data), we estimated the heating $\left(H_{\text {sav }}\right)$ and cooling savings $\left(C_{\text {sav }}\right)$ in (4) and (5): 


$$
\begin{gathered}
H_{\text {sav }}=\left(\frac{1}{R_{\text {conv }}}-\frac{1}{R_{G R}}\right) \times H D D_{15^{\circ} \mathrm{C}} \times 24{\mathrm{hrs} \cdot \text { days }^{-1}}^{-1} \\
C_{\text {sav }}=\left(\frac{1}{R_{\text {conv }}}-\frac{1}{R_{G R}}\right) \times C D D_{18.3^{\circ} \mathrm{C}} \times 24 \mathrm{hrs} \cdot \text { days }^{-1}
\end{gathered}
$$$$
\text { (Error! }
$$$$
\text { Bookmark }
$$$$
\text { not }
$$$$
\text { defined.4) }
$$

(Error!

Bookmark

not

defined.5)

For the monetary valuation, we multiplied the savings by the average price of natural gas for heating of $0.068 €$ per kilowatt hour $(\mathrm{kWh})$ and the average price of electricity for cooling of 0.196 $€ / k W h$ from 2017 (Bundesministerium für Nachhaltigkeit und Tourismus, 2018). Furthermore, we valued the externalities of heating (i.e., additional damage due to carbon dioxide $\left(\mathrm{CO}_{2}\right)$ ) and pollution emissions at $0.05 € / \mathrm{kWh}$ (Matthey and Bünger, 2019).

Greening building surfaces reduce material decay due to weathering (Kosareo and Ries, 2007) as a supporting ecosystem service. On average, conventional roofs either need replacement or largescale maintenance after 25 years (MacMullan et al., 2008; Perini and Rosasco, 2016). Since green roofs extend lifetimes to 50 years on average (Clark et al., 2008) and have even lasted up to 90 years in Berlin, for example (Porsche and Köhler, 2003), we used a cost savings of $62 € / \mathrm{m}^{2}$ for major replacements and sealing repairs (Hämmerle, 2010) at the $25^{\text {th }}$ year as a monetary valuation of this supporting ecosystem service. However, this is a conservative estimate compared to other studies investigating the economic feasibility of green roofs (e.g., Bianchini and Hewage, 2012; Perini and Rosasco, 2016).

For the cultural ecosystem service of aesthetic improvements, we valued increases in the property values of buildings with green roofs. Although a study in New York identified an increase of $16 \%$ in rental rates for buildings with green roofs (Ichihara and Cohen, 2011), most studies estimate property value increases in the range of 2-5\% (e.g., Bianchini and Hewage, 2012; Perini and Rosasco, 2016). We assumed a conservative $3 \%$ increase in the average value of property of various sizes. The average property values from 2016-2018 were 4019, 2423 and $5216 € / \mathrm{m}^{2}$ for Mödling, Klagenfurt and Salzburg, respectively (PWIB Wohnungs-Infobörse GmbH, 2019).

The creation of additional habitats, pollution reduction, and $\mathrm{CO}_{2}$ storage and sequestration comprise the remainder of ecosystem services as societal benefits of green measures. Green roofs provide more natural spaces for organisms as habitats or stopover places (Currie and Bass, 2010), positively contributing to biodiversity as a supporting ecosystem service. We valued this increased provision by taking the cost of restoring land (MacMullan et al., 2008) while scaling down to $15 \%$ to attribute the lower quality of a green roof compared to restored land (Bianchini and Hewage, 2012).

Both trees and green roofs contribute to the reduction of urban air pollutants such as nitrous oxide $\left(\mathrm{NO}_{2}\right)$, ozone $\left(\mathrm{O}_{3}\right)$, sulfur dioxide $\left(\mathrm{SO}_{2}\right)$ and particulate matter (PM) (Yang et al., 2008), and the storage and sequestration of $\mathrm{CO}_{2}$ (Nowak and Crane, 2002; Perini and Rosasco, 2013), both of which are regulating ecosystem services. Table 2 displays the removal and sequestration rates as well as the unit values for the monetary valuation used in this study. Furthermore, we assumed a carbon 
(C) storage rate by trees of $7.57 \mathrm{~kg} \mathrm{C} / \mathrm{m}^{2}$ (Strohbach and Haase, 2012). We adopted the monetary unit values as reduced damages to society for each of the pollutants and used values for $\mathrm{CO}_{2}$ from the German Federal Environment Agency (Matthey and Bünger, 2019).

Table 2. Removal and sequestration rates by trees and green roofs and unit values of air pollutants and $\mathrm{CO}_{2}$.

\begin{tabular}{lrrr}
\hline & \multicolumn{2}{c}{ Removal rates $\left(\mathrm{g} / \mathrm{m}^{2}\right.$-yr $)$} & Unit values $(€ /$ ton $)$ \\
\hline & Trees & Green roofs & \\
\hline $\mathrm{NO}_{2}$ & 3.1 & 2.23 & 17,930 \\
$\mathrm{O}_{3}$ & 4.1 & 4.42 & 2,050 \\
$\mathrm{SO}_{2}$ & 0.4 & 0.595 & 15,040 \\
$\mathrm{PM}_{10}$ & 4.0 & 1.19 & 41,200 \\
$\mathrm{PM}_{2.5}$ & 0.6 & & 58,400 \\
$\mathrm{CO}_{2}$ (sequestered) & 200 & 165 & 180 \\
\hline
\end{tabular}

\subsection{Cost-benefit model}

We adopted unit cost estimates for each of the measures from a combination of literature sources and from expert interviews with local planning authorities in Vienna, Austria (Table 3). For the cost estimates of high albedo measures originating from Bretz et al. (1998), we converted the costs to euros and updated to 2018 values. The costs represent the average costs of a range of high albedo materials to bring about equivalent albedo coefficients as those assumed in the urban climate model. We assume a replacement of the high albedo roofs at the $25^{\text {th }}$ year and therefore included the installation cost discounted to this year. We assume no additional maintenance costs beyond those that would be incurred regardless of the adaptation scenario for high albedo measures and unsealing. For low vegetation, we used the low estimate of the installation costs and maintenance costs for urban parks from Loibl et al. (2015). 
Table 3. Unit costs of high albedo and green measures assumed for all cities.

\begin{tabular}{lrrl}
\hline & $\begin{array}{r}\text { Installation } \\
\left(€ / \mathrm{m}^{2}\right)\end{array}$ & $\begin{array}{r}\text { Maintenance } \\
\left(€ / \mathrm{m}^{2}-\mathrm{yr}\right)\end{array}$ & Source \\
\hline High albedo roofs & 57.23 & 0 & Bretz et al. (1998) \\
High albedo walls & 21.5 & 0 & Bretz et al. (1998) \\
High albedo pavement & 57.67 & 0 & Bretz et al. (1998) \\
Green roofs & 57.00 & 4 & Strehl and Offermann (2017) \\
Unsealing & 20 & 0 & Prokop et al. (2011) \\
Trees & 76.92 & 0.77 & Expert interviews \\
Low vegetation & 56.94 & 3.75 & Loibl et al. (2015) \\
\hline
\end{tabular}

The calculated cost-benefit indices include the net present value (NPV), benefit-cost ratio (BCR), benefit efficiency and cost efficiency. The NPV in (6) is the present value of the benefits $\left(B_{t}\right)$ over the years $(t)$ subtracted from the present value of all costs $\left(C_{t}\right)$, whereas the BCR in (7) is the present value of all benefits divided by the present value of all costs.

$$
\begin{gathered}
N P V=\sum_{t=0}^{t=n} \frac{\left[B_{t}-C_{t}\right]}{(1+r)^{t}} \\
B C R=\frac{\sum_{t=0}^{t=n} \frac{B_{t}}{(1+r)^{t}}}{\sum_{t=0}^{t=n} \frac{C_{t}}{(1+r)^{t}}}
\end{gathered}
$$

(Error!

Bookmark not defined.6)

(Error! Bookmark not defined.7)

An NPV above 0 and BCR above 1 indicates grounds for economic approval of a project, whereas benefit and cost efficiencies allow for comparisons of scenarios in terms of ratios of benefits and costs, respectively, to the overall aim of the project, which is the reduction in the number of hot days. We adopted a social discount rate $(r)$ of 4.1\% (Pálinkó and Szabó, 2012) and conducted the analysis over a time horizon of 50 years.

As high uncertainties in cost-benefit model parameters can lead to highly different outcomes in the NPV, it is important to conduct sensitivity analyses of the model parameters (European Commission, 2014). Hence, a sensitivity analysis was performed using a Monte Carlo simulation in which repeated samples from assumed distributions of parameters are taken to obtain the probability distributions of the cost-benefit indices.

We varied parameters for which realistic variations could lead to significant variation in the NPV. For example, Johnson and Geisendorf (2019) demonstrated high sensitivity in the cost-benefit model parameters including installation and maintenance costs and property value increases for SUDS with similar implemented measures. Therefore, we performed the Monte Carlo simulation with variations in the parameters corresponding to Table 4 . These variations were derived from the 
literature and relevant expert interviews, which resulted in the cost estimations in Table 3, and from relevant literature sources for the habitat creation (Bianchini and Hewage, 2012) and property value increases (Bianchini and Hewage, 2012; Perini and Rosasco, 2016). Furthermore, we simulated changes in the temperature-mortality relationship in a uniform distribution according to the empirically estimated confidence intervals. Lastly, we allowed variations in the precipitation as normal distributions in each city according to city-specific means and standard deviations.

Table 4. Simulated variations in parameters of the cost-benefit model in the Monte Carlo analysis with N(mean, standard deviation) as a normal distribution and $\mathrm{U}($ minimum, maximum) as a uniform distribution of parameters.

\begin{tabular}{lll}
\hline & Distribution and parameters & Units \\
\hline High albedo roofs installation & $\mathrm{U}(45.95,71.64)$ & $€ / \mathrm{m}^{2}$ \\
High albedo walls installation & $\mathrm{U}(16,27)$ & $€ / \mathrm{m}^{2}$ \\
Green roof installation & $\mathrm{N}(57.00,88.41)$ & $€ / \mathrm{m}^{2}$ \\
Green roof maintenance & $\mathrm{N}(4.00,0.64)$ & $€ / \mathrm{m}^{2}$ \\
Tree installation & $\mathrm{N}(1100,400)$ & $€ / \mathrm{m}^{2}$ \\
Habitat creation benefit & $\mathrm{U}(0,30)$ & $\%$ \\
Property value increase & $\mathrm{U}(2,5)$ & $\%$ \\
Discount rate & $\mathrm{U}(2.1,6.1)$ & $\%$ \\
\hline
\end{tabular}

\section{Results}

For the combined scenario for each city, the installation and total maintenance costs to be incurred over the 50 years are presented in Table 5. Maintenance costs are discounted to the year to be incurred to calculate the present value of all costs. For each specific measure, the total costs are estimated by extrapolation from the dimensioning and the unit costs. Installation costs for high albedo roofs include the replacement discounted at the $25^{\text {th }}$ year. 
Table 5. Present value of Installation (I) and annual maintenance (M) costs for each of the cities.

\begin{tabular}{lrrrrrr}
\hline & \multicolumn{2}{c}{ Mödling } & \multicolumn{2}{c}{ Klagenfurt } & \multicolumn{2}{c}{ Salzburg } \\
\hline & $\mathrm{I}(€)$ & $\mathrm{M}(€ / \mathrm{yr})$ & $\mathrm{I}(€)$ & $\mathrm{M}(€ / \mathrm{yr})$ & $\mathrm{I}(€)$ & $\mathrm{M}(€ / \mathrm{yr})$ \\
\hline $\begin{array}{l}\text { High albedo } \\
\text { roofs }\end{array}$ & $178,555,445$ & 0 & $564,467,333$ & 0 & $804,667,947$ & 0 \\
$\begin{array}{l}\text { High albedo } \\
\text { walls }\end{array}$ & $54,884,768$ & 0 & $245,775,006$ & 0 & $262,035,010$ & 0 \\
High albedo & & & & & & \\
pavement & $85,047,822$ & 0 & $692,110,295$ & 0 & $817,726,219$ & 0 \\
Green roofs & & & & & & \\
Unsealing & $31,782,667$ & $47,103,587$ & $118,960,814$ & $176,306,192$ & $155,786,192$ & $230,883,341$ \\
Trees & $8,262,626$ & 0 & $71,064,588$ & 0 & $79,877,310$ & 0 \\
Low vegetation & $7,792,454$ & $14,960,980$ & $5,823,015$ & $11,179,792$ & $8,617,118$ & $16,544,280$ \\
\hline
\end{tabular}

Table 6 displays the result of the valuations for each of the three cities as present values over the 50-year time horizon. Heat-related benefits include the reduced mortality, morbidity, reduced time spent in the hospital, and productivity loss as a result of the adaptation measures.

Salzburg achieved the highest provision of social benefits for the combined adaptation scenario, more than twice that of Klagenfurt. The total value of benefits for Mödling was the lowest of the three cities, which reflects the smaller area and level of implementation of measures for the district. Of all the social benefits valued, the reduction in heat-related mortality represents the largest benefit to society, demonstrating the high societal value in reducing high temperatures. Of the ecosystem services, Mödling demonstrated the highest ratio of green benefits to total benefits with $26 \%$. Klagenfurt and Salzburg were slightly lower in green benefit ratios at $15 \%$ and $12 \%$, respectively.

Table 6. Present value of heat-related benefits and urban ecosystem services (€) discounted at $4.1 \%$ over 50 years for the three cities.

\begin{tabular}{lrrr}
\hline & Mödling & Klagenfurt & Salzburg \\
\hline Reduced mortality & $398,469,450$ & $2,546,207,550$ & $6,108,369,450$ \\
Reduced morbidity & $1,429,348$ & $8,463,836$ & $22,225,418$ \\
Reduced time spent in hospital & 432,456 & $2,763,379$ & $6,629,365$ \\
Reduced productivity loss & $15,299,787$ & $24,003,410$ & $50,258,585$ \\
Runoff reduction & $16,236,729$ & $129,588,570$ & $179,872,651$ \\
Roof longevity increase & $12,660,152$ & $47,386,270$ & $62,055,111$ \\
Cooling savings & $3,990,039$ & $9,759,015$ & $7,363,047$ \\
Heat savings & $14,215,984$ & $61,279,446$ & $76,583,383$ \\
Externalities of heat savings & $10,181,153$ & $43,886,897$ & $54,847,217$ \\
Property value increase & $64,573,747$ & $145,717,993$ & $410,821,309$
\end{tabular}




\begin{tabular}{lrrr} 
Habitat creation & $5,459,722$ & $20,435,446$ & $26,761,420$ \\
Pollution removal & $7,352,431$ & $5,494,202$ & $8,130,529$ \\
$\mathrm{CO}_{2}$ reduction & $9,909,831$ & $7,405,254$ & $10,958,575$ \\
\hline Totals & $560,210,830$ & $3,052,391,267$ & $7,024,876,060$
\end{tabular}

In all cities, the reduction of heat-related mortality represented the largest benefit to society. Increases in property value with green roofs are the second largest benefit across cities, whereas reductions in productivity loss make up a large portion of the benefits for Mödling but to a lesser extent for Klagenfurt and Salzburg. Otherwise, differences in the amount of societal benefits between the cities is reflected in the difference in the dimensioning of the scenarios.

\subsection{Cost-benefit indices}

We calculated the NPV, BCR and cost and benefit efficiencies for each of the three cities for the combined scenario using estimates of the present values of all costs in Table 5 and the present value of all benefits in Table 6. Figure 3 shows the results of the social cost benefit analysis.

With NPVs and BCRs all above 0 and 1, respectively, all three cities result in positive outcomes indicating economic feasibility and hence grounds for adaptation scenario approval. Salzburg obtained the highest benefit given the costs with a BCR of 2.68, whereas Klagenfurt and Mödling were very similar with BCRs of 1.36 and 1.27, respectively. With the cost and benefit efficiencies (i.e., relating costs and benefits to the reduced number of hot days), the cities followed similar trends to the NPVs. For these cities, high benefit efficiencies are associated with high cost efficiencies, meaning that given scenarios with high costs, high benefits can be expected under a wide range of scenarios.

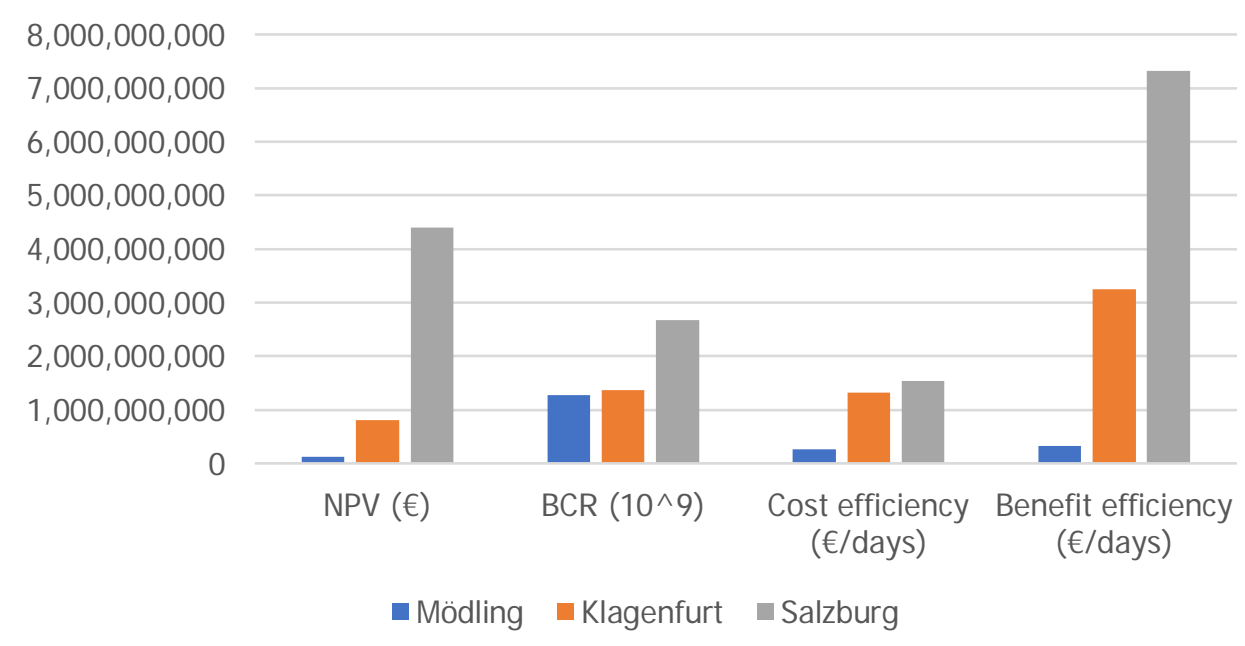

Figure 3. Net present values (NPV), benefit-cost ratios (BCR), cost efficiencies and benefit efficiencies for the combined scenario.

\subsection{Green vs White City scenarios}


We calculated the NPV, BCR and cost and benefit efficiencies for each of the three cities for the combined, Green City and White City scenarios. As before, we use estimates of the present values of all costs in Table 5 and the present value of all benefits in Table 6 for calculation of the cost-benefit indices.

Figure 4a displays the comparison of scenarios for Mödling. Despite the high costs associated with the Green City scenario, this scenario achieved the highest benefit efficiency, demonstrating the numerous additional benefits provided through the monetary valuation of the urban ecosystem services. The White City scenario maintains the lowest costs given the highest BCR and lowest cost efficiency out of the three scenarios. Therefore, the White City scenario provides the high benefits through reductions in heat-related mortality given the low cost of measures relative to the green measures, but this scenario resulted in a negative outcome. The lowest benefit efficiency is also provided with this scenario, attributing to the lack of urban ecosystem services.

Similar results to Mödling were achieved for both Klagenfurt and Salzburg in the comparison of the Green City and White City scenarios (see Fig. 4b and c). The high costs of the green scenarios equally brought about higher benefits, leading to higher benefit efficiencies, whereas the low costs of the White City scenarios are not reconciled with equivalent levels of benefits. This results in lower BCRs and higher cost efficiencies for the White City scenario for all cities. However, in the case of Klagenfurt, the combined scenario has the highest benefit efficiency, due to the relatively low reduced annual number of hot days in the Green and White City scenarios ( $\sim 0.5$ hot day on average). Furthermore, only in the case of Salzburg was the NPV the highest for the combined scenario of measures, which reflects the high sensitivity of the population to temperature in the heat-related benefits.

\section{(a) Mödling}

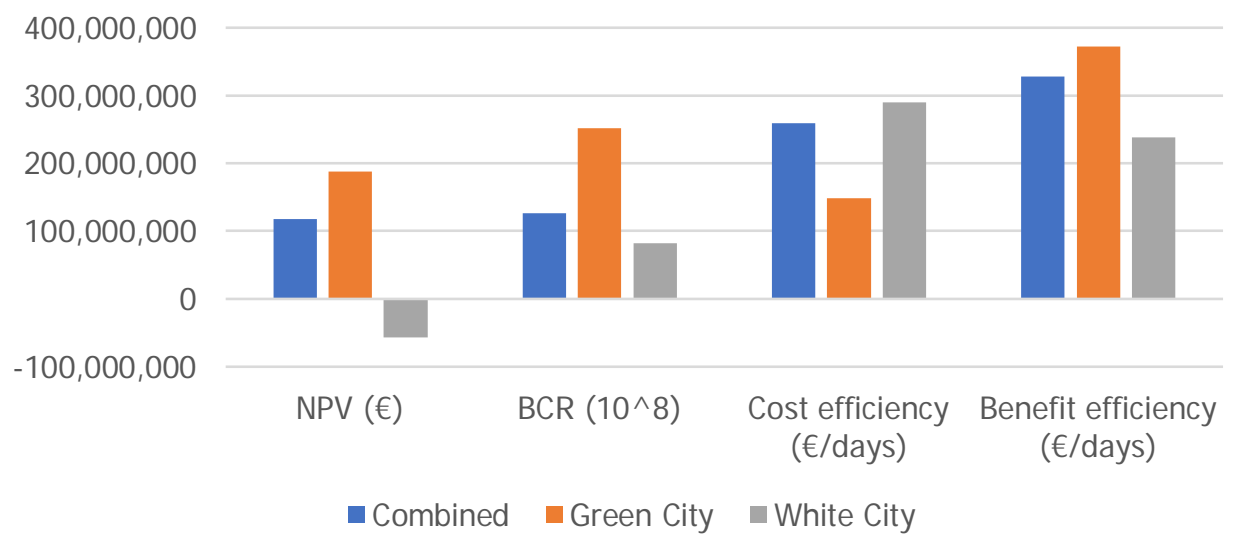


(b) Klagenfurt

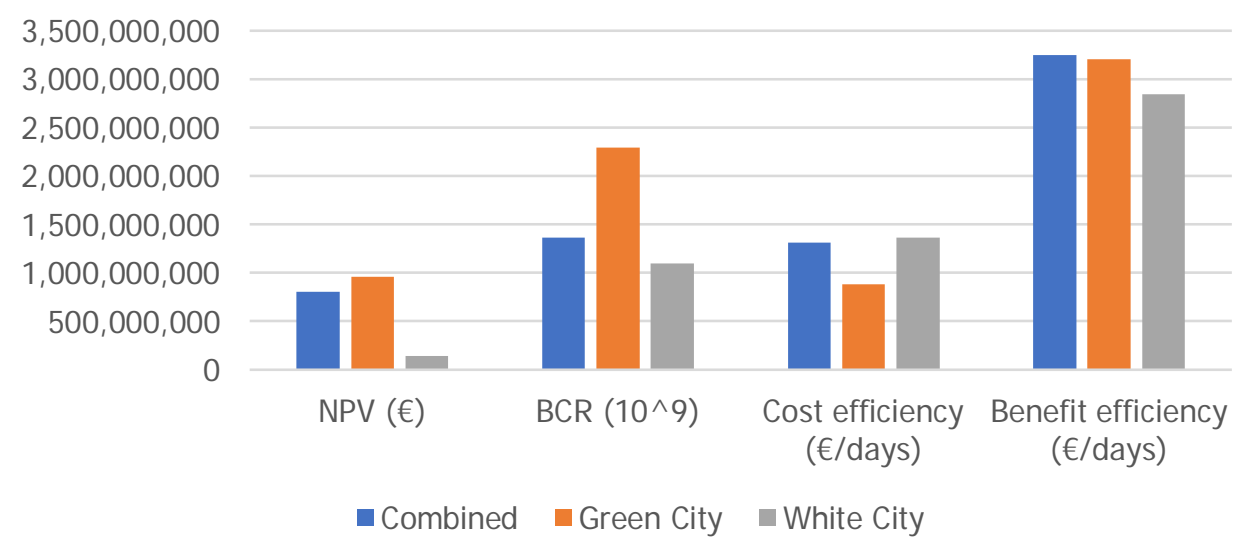

(c) Salzburg

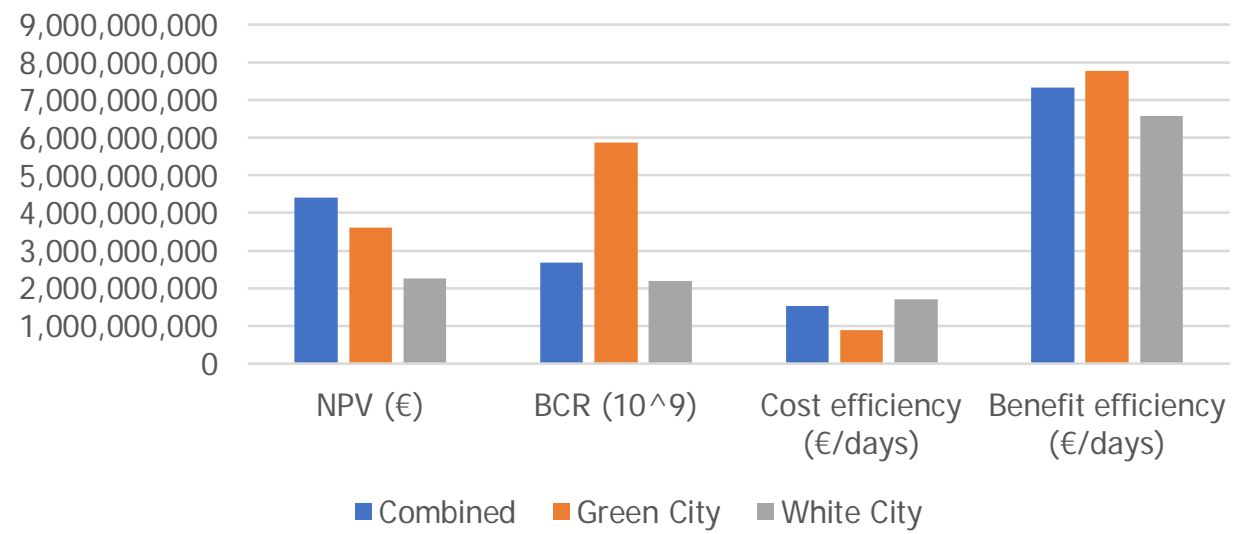

Figure 4. Cost-benefit indices of the combined, Green City and White City scenarios for (a) Mödling, (b) Klagenfurt and (c) Salzburg.

\subsection{Sensitivity analysis}

A sensitivity analysis was performed using a Monte Carlo simulation with 10,000 iterations, which ensures that the numerous possible combinations of variations could be simulated randomly. Figure S2 in the Supplementary Material shows the results of the Monte Carlo analysis as cumulative probability distributions for the combined scenarios of measures for each of the cities. By means of the cumulative probability curves, we assess the risk of the combined scenarios.

The probabilities of a project obtaining a positive NPV were 88\%, 73\% and 100\% for Mödling, Klagenfurt and Salzburg, respectively. Therefore, the results for Mödling and Salzburg are very robust in terms of obtaining a positive outcome. For Klagenfurt, the lower property prices compared to Mödling and Salzburg become very relevant in testing the sensitivity of the property value increase. Thus, although Klagenfurt achieves a higher BCR than Mödling, for example, the variability in parameters leads to higher risk in the combined scenario for this city. This is also apparent in the probability of achieving the baseline combined scenarios in Figure 3. Although Mödling and Salzburg 
have likelihoods of achieving the baseline of $52 \%$ and $46 \%$, respectively, Klagenfurt has a likelihood of $20 \%$.

\section{Discussion}

In this study, we investigated the economic feasibility of UHI adaptation scenarios for three small- to medium-sized cities using a CBA. Thereby, we have addressed not only the research gap in analyzing the UHI effect but also in green infrastructure planning and ecosystem service research in small- to medium-sized cities.

We find that the benefits do outweigh the costs for a variety of scenarios including green and white measures as well as a combination of both. In all cities, the combined and Green City scenarios demonstrated economic feasibility. Only for the White City scenario in Mödling was a negative result obtained. Furthermore, in every city, the cost efficiencies were the highest for the White City scenario, and the benefit efficiencies were the highest for the Green City and combined scenarios. This demonstrates that although urban ecosystem services obtained by green measures only make up small percentages of the overall benefits (12-25\%), there are still large values to society involved, which can further push the scenarios in a positive direction. Therefore, adopting White City scenarios may directly address the issues of UHI, but greater opportunities are provided to address multiple urban issues at once by implementing combined or Green City scenarios. This offers even small and medium-sized cities a chance in developing frameworks for multifunctionality (Hansen and Pauleit, 2014). Therefore, by pursuing such scenarios, urban planners and policy makers create societal value and robustly address multiple urban issues simultaneously, which can promote public support and stymie public scrutiny.

Despite positive results across almost all scenarios, it should be recognized that the value of reduced heat-related mortality represented the largest benefit in each of the scenarios. Despite this, we maintain the stance that the quality of the analysis lies not only with the specific estimation of heat-related mortality for the three cities but also with the spatially-explicit approach of addressing exposure to the risk. Previous CBAs covering economic appraisals of heat waves and warning systems estimate heat-related mortality reductions using relative risks modeled at regional scales (e.g., Hunt et al., 2017; Stone et al., 2014) or adopted from other cities (e.g., Xia et al., 2018). Therefore, the epidemiological approach utilized in the present study takes a more precise approach to account for the impact of this benefit in the CBA.

Although the literature on heat-related mortality is rich, the current study makes general and methodological contributions to the literature on adaptation to heat stress. Chen et al. (2014) and Dang et al. (2017) showed how heat-related mortality decreases with increased provision of vegetation and green space in urban contexts, respectively. Stone et al. (2014) developed adaptation scenarios including green measures for three U.S. cities and demonstrated significant decreases in heat-related mortality. None of these studies quantified the costs and benefits monetarily. From an economic perspective, several studies have investigated different strategies for addressing heat stress. For example, Chiabai et al. (2018) investigated the economic viability of heat-warning systems in Madrid and found high societal benefits in terms of reduced heat-related mortality. Likewise, Hunt et al. (2017) demonstrated the economic feasibility of such systems for several European regions while also incorporating a spatial context (i.e., $25 \mathrm{~km} \mathrm{x} 25 \mathrm{~km}$ grids) for calculating heat-attributable deaths. Some studies have economically estimated reduced UHI effects by monetarily valuing 
reduced heat-related mortality but they failed to quantify additional benefits associated with green measures (Mills and Kalkstein, 2012). Therefore, our study is novel on many fronts by introducing a fine scale approach, empirically estimating heat-related mortality and economically analyzing the efficiency of such adaptation scenarios with green measures.

Some limitations of this research should be noted. First, we did not consider the impact of climate change in our analysis for several reasons. Climate change projections introduce new uncertainty into the modeling, and there is a lack of evidence regarding the change in the temperaturemortality relationship in terms of individual adaptation to higher temperatures (Gasparrini et al., 2017). Moreover, we have adopted a more general bottom-up approach for the CBA, and climate projections stemming from regional models would introduce uncertainties, as these would need to be dynamically downscaled to a fine detail, as our current analysis utilized $250 \mathrm{~m}$ x $250 \mathrm{~m}$ raster grids. Second, we did not include changes to the demographic characteristics of the populations over time, as these estimates would also be very uncertain and highly aggregated. Therefore, the approach used in this study was to assume a changed state with the scenario of measures and then propagate this into future years. Further limitations in regard to the data sources should also be acknowledged. Although we gathered the most up-to-date and context-specific data possible, we acknowledge that some sources stem from several years prior, and there is a need for more current research addressing the costs and impact performance of the different measures. However, we maintain the stance that the values obtained served the purpose as guiding values for the completion of such a CBA for the current study.

\section{Conclusion}

In this paper, we developed a novel approach for estimating the economic feasibility of three scenarios to mitigate the UHI effect in small and medium-sized cities in Austria. The CBA showed net positive contributions to society when a combination of all measures (i.e., the Green and White City) are implemented. When comparing the Green vs White City scenarios, positive economic outcomes were estimated for all cities, but higher benefits were obtained for the Green City despite the higher costs associated with the green measures. Although the White City scenario still yields sizable benefits for lower costs, the green measures provide additional benefits through improved urban ecosystem services. Although this paper has considered small- to medium-sized cities, the methods are applicable in different contexts and to cities of various sizes.

Although the CBA incorporated the affect of extreme heat on human health in a spatial manner, some limitations remained in developing a comprehensive approach to modeling these impacts. Due to a lack of data at such fine scales, we could not account for differentiations in labor productivity across indoor and outdoor workers or the presence of air conditioning. Further research could incorporate current and future uptake of air-conditioned workplaces and disaggregate labor productivity improvements with adaptation into outdoor and indoor environments. Such analyses would improve the accuracy and estimations of exposure of residents in analyzing the human healthrelated impacts of extreme heat.

Generally, the results of the urban climate model adaptation simulations and the CBA were well received by city officials and urban planners in the three cities of this project, and strategies for adapting to the UHI effect are still being designed. When urban planners are faced with many different adaptation measures, a combination of urban climate model adaptation simulations and a 
CBA can provide crucial information on what measures can be feasibly implemented as well as ensuring that such policies lead to an increase in societal welfare.

\section{References}

Berardi U, Ghaffarianhoseini AmirHosein and Ghaffarianhoseini Ali (2015) State-of-the-art analysis of the environmental benefits of green roofs. Applied Energy 115: 411-428. DOI: https://doi.org/10.1016/j.apenergy.2013.10.047.

Bianchini F and Hewage K (2012) Probabilistic social cost-benefit analysis for green roofs: A lifecycle approach. Building and Environment 58: 152-162. DOI: 10.1016/j.buildenv.2012.07.005.

Bolund P and Hunhammer S (1999) Ecosystem services in urban areas. Ecological Economics 29(2): 293-301. DOI: 10.1016/S0921-8009(99)00013-0.

Bretz S, Akbari H and Rosenfeld A (1998) Practical issues for using solar-reflective materials to mitigate urban heat islands. Atmospheric Environment 32(1): 95-101. DOI: 10.1016/S13522310(97)00182-9.

Bundesministerium für Nachhaltigkeit und Tourismus (2018) Energie in Österreich 2018. Report. Vienna.

Bux K (2006) Klima am Arbeitsplatz - Stand arbeitswissenschaftlicher Erkenntnisse Bedarfsanalyse für weitere Forschungen. Bundesamt für Arbeitsschutz und Arbeitsmedizin, Dortmund.

Chen D, Wang X, Thatcher M, et al. (2014) Urban vegetation for reducing heat related mortality. Environmental Pollution 192(May). Elsevier Ltd: 275-284. DOI: 10.1016/j.envpol.2014.05.002.

Chiabai A, Spadaro J V. and Neumann MB (2018) Valuing deaths or years of life lost? Economic benefits of avoided mortality from early heat warning systems. Mitigation and Adaptation Strategies for Global Change 23(7). Mitigation and Adaptation Strategies for Global Change: 1159-1176. DOI: 10.1007/s11027-017-9778-4.

Clark C, Adriaens P and Talbot FB (2008) Green roof valuation: a probabilistic economic analysis of environmental benefits. Environmental Science \& Technology 42(6). American Chemical Society: 2155-2161. DOI: 10.1021/es0706652.

Currie BA and Bass B (2010) Using Green Roofs to enhance Biodiversity in the City of Toronto. Discussion Paper for Toronto City Planning. Toronto.

Dang TN, Van DQ, Kusaka H, et al. (2018) Green Space and Deaths Attributable to the Urban Heat Island Effect in Ho Chi Minh City. American Journal of Public Health 108(S2): S137-S143. DOI: $10.2105 /$ AJPH.2017.304123.

Dehnhardt A (2014) Zur Ökonomisierung umweltpolitsicher Entscheidungsfindung. Ökologisches Wirtschaften 29(2): 22-24. DOI: 10.14512/OEW290222.

Donaldson G, Kovats RS, Keatinge WR, et al. (2001) Heat- and cold-related mortality and morbidity and climate change. In: Health Effects of Climate Change in the UK. London: Department of Health, pp. 70-80.

European Commission (2014) Guide to Cost-Benefit Analysis of Investment Projects. Economic Appraisal Tool for Cohesion Policy, 2014-2020. DOI: 10.2776/97516.

Forzieri G, Cescatti A, e Silva FB, et al. (2017) Increasing risk over time of weather-related hazards to the European population: a data-driven prognostic study. The Lancet Planetary Health 1(5): 
e200-e208. DOI: 10.1016/S2542-5196(17)30082-7.

Frederick S (2003) Measuring Intergenerational Time Preference: The Journal of Risk and Uncertainty 26(1): 39-53. DOI: doi.org/10.1023/A:1022298223127.

Früh B, Becker P, Deutschländer T, et al. (2011) Estimation of Climate-Change Impacts on the Urban Heat Load Using an Urban Climate Model and Regional Climate Projections. Journal of Applied Meteorology and Climatology 50(1): 167-184. DOI: 10.1175/2010JAMC2377.1.

Gasparrini A and Armstrong B (2011) The Impact of Heat Waves on Mortality. Epidemiology 22(1): 68-73. DOI: 10.1097/EDE.0b013e3181fdcd99.

Gasparrini A and Leone M (2014) Attributable risk from distributed lag models. BMC Medical Research Methodology 14(1): 1-8. DOI: 10.1186/1471-2288-14-55.

Gasparrini A, Guo Y, Sera F, et al. (2017) Projections of temperature-related excess mortality under climate change scenarios. The Lancet Planetary Health 1(9): e360-e367. DOI: 10.1016/S25425196(17)30156-0.

Gasparrinia A, Armstrong B and Kenward MG (2010) Distributed lag non-linear models. Statistics in Medicine 29(21): 2224-2234. DOI: 10.1002/sim.3940.

Hämmerle F (2010) Die Wirtschaftlichkeit von Gründächern aus der Sicht des Bauherrn. Available at: http://www.haemmerle-gruendach.de/artigr/wirtvongd.html (accessed 11 December 2017).

Hansen R and Pauleit S (2014) From multifunctionality to multiple ecosystem services? A conceptual framework for multifunctionality in green infrastructure planning for urban areas. AMBIO 43(4): 516-519. DOI: 10.1007/s13280-014-0510-2 From.

Harlan SL and Ruddell DM (2011) Climate change and health in cities: impacts of heat and air pollution and potential co-benefits from mitigation and adaptation. Current Opinion in Environmental Sustainability 3(3): 126-134. DOI: 10.1016/j.cosust.2011.01.001.

Hidalgo J, Pigeon G and Masson V (2008) Urban-breeze circulation during the CAPITOUL experiment: Observational data analysis approach. Meteorology and Atmospheric Physics 102(3-4): 223-241. DOI: 10.1007/s00703-008-0329-0.

Hübler M, Klepper G and Peterson S (2008) Costs of climate change. The effects of rising temperatures on health and productivity in Germany. Ecological Economics 68(1-2). Kiel Working Paper No.1321. Elsevier B.V.: 381-393. DOI: 10.1016/j.ecolecon.2008.04.010.

Hunt A, Ferguson J, Baccini M, et al. (2017) Climate and weather service provision: Economic appraisal of adaptation to health impacts. Climate Services 7. The Authors: 78-86. DOI: 10.1016/j.cliser.2016.10.004.

Ichihara K and Cohen JP (2011) New York City property values: What is the impact of green roofs on rental pricing? Letters in Spatial and Resource Sciences 4(1): 21-30. DOI: 10.1007/s12076010-0046-4.

Johnson D and Geisendorf S (2019) Are Neighborhood-level SUDS Worth it? An Assessment of the Economic Value of Sustainable Urban Drainage System Scenarios Using Cost-Benefit Analyses. Ecological Economics 158(December 2018). Elsevier: 194-205. DOI: 10.1016/j.ecolecon.2018.12.024.

Karlsson M and Ziebarth NR (2018) Population health effects and health-related costs of extreme temperatures: Comprehensive evidence from Germany. Journal of Environmental Economics and Management 91. Elsevier Inc.: 93-117. DOI: 10.1016/j.jeem.2018.06.004.

Kosareo L and Ries R (2007) Comparative environmental life cycle assessment of green roofs. 
Building and Environment 42(7): 2606-2613. DOI: 10.1016/j.buildenv.2006.06.019.

Loibl W, Trötzer T, Köstl M, et al. (2015) Cities and urban green. In: Steininger K, König M, BednarFriedl B, et al. (eds) Economic Evaluation of Climate Change Impacts. Cham: Springer, pp. 323-347.

MacMullan E, Reich S, Puttman T, et al. (2008) Cost-Benefit Evaluation of Ecoroofs. In: Low Impact Development for Urban Ecosystem and Habitat Protection, 2008, pp. 1-10. DOI: 10.1061/41009(333)87.

Matthey A and Bünger B (2019) Methodenkonvention 3.0 zur Ermittlung von Umweltkosten Kostensätze. Umweltbundesamt, Dessa-Roßlau. Available at: https://www.umweltbundesamt.de/sites/default/files/medien/1410/publikationen/2019-0211_methodenkonvention-3-0_kostensaetze_korr.pdf.

Mills D and Kalkstein L (2012) Estimating Reduced Heat-Attributable Mortality for an Urban Revegetation Project. Journal of Heat Island Institute International 7(2): 18-24.

Mughal MO, Li X, Yin T, et al. (2019) High-Resolution, Multilayer Modeling of Singapore’s Urban Climate Incorporating Local Climate Zones. Journal of Geophysical Research: Atmospheres: 2018JD029796. DOI: 10.1029/2018JD029796.

Nowak DJ and Crane DE (2002) Carbon storage and sequestration by urban trees in the USA. Environmental Pollution 116(3): 381-389. DOI: 10.1016/S0269-7491(01)00214-7.

Oke TR (1973) City size and the urban heat island. Atmospheric Environment (1967) 7(8): 769-779. DOI: 10.1016/0004-6981(73)90140-6.

Oke TR (1982) The energetic basis of the urban heat island. Quarterly Journal of the Royal Meteorological Society 108(455): 1-24. DOI: 10.1002/qj.49710845502.

Oswald SM, Hollosi B, Žuvela-Aloise M, et al. (2020) Using urban climate modelling and improved land use classifications to support climate change adaptation in urban environments: A case study for the city of Klagenfurt, Austria. Urban Climate 31: 100582. DOI: 10.1016/j.uclim.2020.100582.

Pálinkó É and Szabó M (2012) Application of Social Discount Rate in Public Projects. Public Finance Quarterly 57(2): 184-199.

Perini K and Rosasco P (2013) Cost-benefit analysis for green façades and living wall systems. Building and Environment 70: 110-121. DOI: 10.1016/j.buildenv.2013.08.012.

Perini K and Rosasco P (2016) Is greening the building envelope economically sustainable? An analysis to evaluate the advantages of economy of scope of vertical greening systems and green roofs. Urban Forestry \& Urban Greening 20: 328-337. DOI: 10.1016/j.ufug.2016.08.002.

Porsche U and Köhler M (2003) Life cycle costs of green roofs--A comparison of Germany, USA, and Brazil. In: RIO 3 - World Climate \& Energy Event, Rio de Janeiro, 2003, pp. 461-467. DOI: 10.1007/s00158-009-0416-y.

Prokop G, Jobstmann H and Schönbauer A (2011) Report on Best Practices for Limiting Soil Sealing and Mitigating Its Effects. DOI: 10.1016/J.ENVRES.2017.03.032.

PWIB Wohnungs-Infobörse GmbH (2019) Immobilienpreisentwicklung und Preistrend in Österreich: aktuelle Immobilienspiegel. Available at: https://www.wohnungsboerse.net/immobilienpreise-oesterreich (accessed 25 July 2019).

Revi A, Satterthwaite DE, Aragón-Durand F, et al. (2014) Urban Areas. In: Field CB, Barros VR, Dokkon DJ, et al. (eds) Climate Change 2014: Impacts, Adaptation, and Vulnerability. Part A: 
Global and Sectoral Aspects. Contribution of Working Group II to the Fifth Assessment Report of the Intergovernmental Panel on Climate Change. Cambridge, United Kingdom, New York: Cambridge University Press, pp. 535-612.

Robinson LA, Hammitt JK and O’Keeffe L (2019) Valuing Mortality Risk Reductions in Global Benefit-Cost Analysis. Journal of Benefit-Cost Analysis 10: 15-50. DOI: 10.1017/bca.2018.26.

Shackleton CM, Blair A, De Lacy P, et al. (2018) How important is green infrastructure in small and medium-sized towns? Lessons from South Africa. Landscape and Urban Planning 180. DOI: 10.1016/j.landurbplan.2016.12.007.

Sievers U (1995) Generalization of the stream-function method to three dimensions. Meteorologische Zeitschrift 4: 3-15.

Stone B, Vargo J, Liu P, et al. (2014) Avoided Heat-Related Mortality through Climate Adaptation Strategies in Three US Cities. Linkov I (ed.) PLoS ONE 9(6): e100852. DOI: 10.1371/journal.pone.0100852.

Strehl C, Offermann M, Hein A, et al. (2017) Schlussbericht des Forschungsvorhabens KURAS. IWW-Teilbericht: Ökonomische Effekte der Regenwasserbewirtschaftung am Beispiel Berlins. Berlin.

Strohbach MW and Haase D (2012) Above-ground carbon storage by urban trees in Leipzig, Germany: Analysis of patterns in a European city. Landscape and Urban Planning 104(1). Elsevier B.V.: 95-104. DOI: 10.1016/j.landurbplan.2011.10.001.

UNEP (2004) Impacts of summer 2003 heat wave in Europe. Environment Alert Bulletin.

Viscusi WK and Masterman CJ (2017) Income Elasticities and Global Values of a Statistical Life. Journal of Benefit-Cost Analysis 8(2): 226-250. DOI: 10.1017/bca.2017.12.

Vöhringer F, Vielle M, Thurm B, et al. (2017) Assessing the impacts of climate change for Switzerland. The Federal Office for the Environment, Bern, Switzerland.

Xia Y, Li Y, Guan D, et al. (2018) Assessment of the economic impacts of heat waves: A case study of Nanjing, China. Journal of Cleaner Production 171. Elsevier Ltd: 811-819. DOI: 10.1016/j.jclepro.2017.10.069.

Yang J, Yu Q and Gong P (2008) Quantifying air pollution removal by green roofs in Chicago. Atmospheric Environment 42(31): 7266-7273. DOI: 10.1016/j.atmosenv.2008.07.003.

Zhang G, He BJ, Zhu Z, et al. (2019) Impact of morphological characteristics of green roofs on pedestrian cooling in subtropical climates. International Journal of Environmental Research and Public Health 16(2). DOI: 10.3390/ijerph16020179. 